\title{
Optimum design parameter determination of biogas digester using human faeces feedstock
}

\author{
Nuhu M. ${ }^{1 \star}$, Mujahid M.M ${ }^{6}$, Aminu A. Hamisu ${ }^{1}$, Abbas A. J $^{1}$, Babangida D. ${ }^{2}$, Tsunatu D. ${ }^{3}$, Aminu \\ Y. $Z^{4}$, Mustapha $Y^{1}$, Ahmed $I^{5}$ and Onukak I. $E^{7}$ \\ ${ }^{1}$ Department of Chemical Engineering, Ahmadu Bello University, Zaria, Nigeria. \\ ${ }^{2}$ Bayero University Kano, Nigeria. \\ ${ }^{3}$ Department of Chemistry, Taraba State University, Nigeria. \\ ${ }^{4}$ Nigerian National Petroleum Corporation (NNPC), Nigeria. \\ ${ }^{5}$ Department of Chemical Engineering, Abubakar Tafawa Balewa University (ATBU), Bauchi State, Nigeria. \\ ${ }^{6}$ Department of Water Resources and Engineering Ahmadu Bello University, Zaria, Nigeria. \\ ${ }^{7}$ Nigerian Institute of Leather and Science Technology, (NILEST), Zaria.
}

Accepted 1 May, 2013

\begin{abstract}
Biogas digester operation depends majorly on $\mathrm{C} / \mathrm{N}$ ratio, hydraulic retention time, $\mathrm{pH}$, temperature, and mixing ratio of the domestic waste used. Temperature of 15 to $45^{\circ} \mathrm{C}, \mathrm{C} / \mathrm{N}$ ratio of 20 to 30 , Hydraulic retention time of 1 to 30 days, mixing ratio of 10 to $20 \% \mathrm{w} / \mathrm{v}$ and $\mathrm{pH}$ of 6.5 to 8 were considered for the analysis. Analysis of Variance (ANOVA) was used to test whether there are statistically significant differences between two or more independent groups using Design Expert Software. The R-square values are $0.933,0.943$ and 0.919 for mean, standard deviation and coefficient of variance respectively. These values were found to be in reasonable agreement with standards. Retention time is the only factor that is not involved in the interactions among the four significant factors selected out of the five factors under consideration. The maximum biogas yield was $86.24 \%$ at retention time of 30 days, temperature of $45^{\circ} \mathrm{C}, \mathrm{pH}$ value of 6.5 , mixing ration of $10 \% \mathrm{w} / \mathrm{v}$, and carbon to nitrogen ratio of 20 respectively.
\end{abstract}

Key words: Biogas, experiment, analysis of variance (ANOVA), faeces, digester, yield.

\section{INTRODUCTION}

More than 2.6 billion people lack access to a hygienic method for the disposal of human waste (World Health Organization, 2010). They defecate in open fields, behind bushes, in buckets, nylon bags or in latrines suspended over water sources or open pits. These practices contribute to the spread of disease and degrade the quality of water resources. Globally, diarrhoeal diseases attributable to the lack of safe water and basic sanitation cause 1.6 million deaths each year (United Nations Children's Fund, 2006).
Human faeces represent a potential source of methane, which can be used as fuel for cooking, or in other heating applications. The process of converting human excrement and other organic residues into methane, carbon dioxide and other gases is term anaerobic digestion, is a well-established process. It occurs naturally wherever high concentrations of wet organic matter accumulate in the absence of dissolved oxygen.

Anaerobic digestion is a process that breaks organic 
matter such as kitchen, agricultural, human and animal wastes, into useable end products through a series of microbial mediated biological reactions. The gas produced by digestion, known as marsh gas, sewage gas, dun gas, or bio-gas, is about $70 \%$ methane $\left(\mathrm{CH}_{4}\right)$ and $29 \%$ carbon dioxide $\left(\mathrm{CO}_{2}\right)$ with insignificant traces of oxygen and hydrogen sulphide $\left(\mathrm{H}_{2} \mathrm{~S}\right)$, which gives the gas a distinct odor with a heat value of approximately $36,500 \mathrm{~kJ} / \mathrm{m}^{3}$ (John, 2012; Deublein and Steinhauser, 2008).

Design Expert is a piece of software designed to help with the design and interpretation of multi-factor experiments. It offers computer generated D-optimal designs for cases where standard designs are not applicable, or where we wish to augment an existing design - for example, to fit a more flexible model (Montgomery, 2001). The factors that we vary in experiment can be divided into Process variables, such as the speed of an engine or the thickness of an adhesive layer, and Mixture variables, such as the proportion of resin in a plastic compound, or the proportion of fat in a chicken feed. With a mixture variable, the effect depends on the proportion of a constituent in the mixture, rather than on the absolute amount (Montgomery, 2005).

In analyzing an experiment, we fit models relating a response or quality characteristic to a set of controllable variables. For continuous control variables, we often use a linear, factorial or quadratic model - for example. . .

Linear model $Y=\beta_{0}+\beta_{1} X_{1}+\beta_{2} X_{2}+\varepsilon$

Factorial model $Y=\beta_{0}+\beta_{1} X_{1}+\beta_{2} X_{2}+\beta_{12} X_{1} X_{2}+\varepsilon$

Quadratic model $Y=\beta_{0}+\beta_{1} X_{1}+\beta_{2} X_{2}+\beta_{12} X_{1} X_{2}+\beta_{11} X_{21}$ $+\beta_{22} X_{22}+\varepsilon$

Apart from the intercept, the terms in these models fall into one of three categories

1. Linear terms (Main effects) of the form $\beta_{i} X_{i}$.

- model the average effect of varying a control.

2. Two-factor interactions of the form $\beta_{i j} X_{i} X_{j}$.

- allow the effect of changing a control to vary with the setting of another control.

3. Quadratic terms of the form $\beta_{i i} X_{i 2}$.

- allow for curvature in the effect of a control on the response.

Models for categorical controls often involve a set of terms to represent a single main effect or two-factor interaction, but the interpretation of the effects is similar (Wu and Hamada, 2000).

This work tends to determine the optimum design parameters of biogas digester from human faeces using Design Expert Software.

\section{METHODOLOGY}

The Analysis of Variance (ANOVA) is a technique commonly used to test whether there are statistically significant differences between two or more independent groups. These groupings are made on the basis of levels of independent variables. The outcome of performing ANOVA is an F ratio, which can be used to determine whether statistically significant difference exist between the groups. The $F$ test for ANOVA is simply the ratio between the sum of squares between and sum of squares within. Thus, if the variation between samples becomes relatively large compared to the variation within samples, the group is expected to be drawn from different populations and a significant difference to exist.

The study of the effects (main effects and interaction effects) of the factors affecting biogas digester design was done using the full factorial design of experiment. The effect of retention time $(A)$, temperature $(B), \mathrm{pH}(\mathrm{C})$, mixing ratio $(\mathrm{D})$, and carbon to nitrogen ratio $(E)$ on the response of yield of biogas were also investigated. Base on $2^{n}$ principle built in the Design Expert 6.0 software, 32 experiments were conducted with each factor varied at 2-level of high and low (Table 1). The software then uses contrast of average base on this designed experiment to generate model equations describing the biogas yield as a function of these design parameters.

$\mathrm{Y}=f(\mathrm{~A}, \mathrm{~B}, \mathrm{C}, \mathrm{D}, \mathrm{E})$

$Y=\alpha A+\beta B+y C+\mu D+8 E+\partial A B+\varnothing C E+\gamma A D+\varepsilon B D+\gamma D E+$ $\lambda C D+\ominus A B C+\gamma A C D+\S B C D+8 A B D+\lceil A B C D$

\section{RESULTS AND DISCUSSION}

The results of the 32 experimental runs are summarized in Table 2. The yield ranges from 23.07 to $86.24 \%$, the ratio of the maximum to minimum is 3.74 . A ratio greater than 10 usually indicates the need for transformation. Therefore there is no need for transformation with respect to the ratio obtained in this research. Table 4 present the percentage contribution of this picked effects to the model (Table 3); for the main effect mixing ratio (dry matter content) was found to be the most significant $(40.9 \%)$, this was followed by $\mathrm{pH}$ value $(30.1 \%)$, temperature (7.835), Carbon to Nitrogen ratio (7.33\%) and Retention time (2.52\%). However, for the interaction effects: the combine effect of mixing ratio with $\mathrm{pH}$ was found to be higher (1.64\%) followed by temperature/mixing ratio $(1.42 \%)$, mixing ratio to carbon/nitrogen ratio $(1.36 \%)$ and finally mixing ratio to carbon/nitrogen ratio $(1.24 \%)$. For the main effects carbon/nitrogen $(E)$ ratio and $\mathrm{pH}(\mathrm{C})$ affect the model negatively while retention time $(A)$, temperature $(B)$ and mixing ratio $(D)$ has positive effect on the model. For the interaction effects $\mathrm{pH} /$ mixing ratio $(\mathrm{CD})$ and mixing ratio/carbon to nitrogen ratio (DE) affect the model negatively while temperature/mixing ratio (BD) and $\mathrm{pH} /$ carbon to nitrogen ratio (CE) has positive effect on the model.

The model $F$ value of 98.5 (Table 4) implies the model is significant. There is only $0.01 \%$ chance than the model $F$ value; this difference could be due to noise. Values of prob $>\mathrm{F}$ less than 0.05 indicates model terms are significant. In this case A, B, C, D, F, BD, CD, CE and DE are significant model terms. Table 5 gives the value of 
Table 1. Low and high values for the operating parameters.

\begin{tabular}{clcccccc}
\hline Factor & Name & Units & Type & Low actual & High actual & Low coded & High coded \\
\hline A & Retention time & days & Numeric & 1 & 30 & -1 & 1 \\
B & Temperature & ${ }^{\circ} \mathrm{C}$ & Numeric & 15 & 45 & -1 & 1 \\
C & pH & - & Numeric & 6.5 & 8 & -1 & 1 \\
D & Mixing ratio & $\% \mathrm{w} / \mathrm{v}$ & Numeric & 8 & 10 & -1 & 1 \\
$\mathrm{E}$ & C/N ratio & & Numeric & 20 & 30 & -1 & 1 \\
\hline
\end{tabular}

Table 2. Result summary.

\begin{tabular}{cccccccc}
\hline Std. & Run & Time (days) & Temperature $\left({ }^{\circ} \mathbf{C}\right)$ & $\mathbf{p H}$ & Mixing ratio $(\% \mathbf{w} / \mathbf{v})$ & Carbon/Nitrogen & Yield $(\%)$ \\
\hline 27 & 1 & 1 & 45 & 6.5 & 10 & 30 & 81.93 \\
18 & 2 & 30 & 15 & 6.5 & 8 & 30 & 50.24 \\
32 & 3 & 30 & 45 & 8 & 10 & 20 & 55.86 \\
11 & 4 & 30 & 45 & 6.5 & 10 & 20 & 86.24 \\
55 & 5 & 1 & 45 & 8 & 8 & 30 & 30.36 \\
57 & 6 & 1 & 15 & 6.5 & 10 & 30 & 50.61 \\
29 & 7 & 1 & 15 & 8 & 10 & 20 & 40.80 \\
62 & 8 & 30 & 15 & 8 & 10 & 30 & 41.67 \\
3 & 9 & 1 & 45 & 6.5 & 8 & 20 & 56.06 \\
61 & 10 & 1 & 15 & 8 & 10 & 30 & 35.42 \\
59 & 11 & 30 & 45 & 6.5 & 10 & 30 & 63.26 \\
64 & 12 & 30 & 45 & 8 & 10 & 30 & 52.09 \\
5 & 13 & 1 & 15 & 8 & 8 & 20 & 27.92 \\
2 & 14 & 30 & 15 & 6.5 & 8 & 20 & 52.88 \\
24 & 15 & 30 & 45 & 8 & 8 & 30 & 36.32 \\
37 & 16 & 1 & 15 & 8 & 8 & 20 & 23.07 \\
53 & 17 & 1 & 15 & 8 & 8 & 30 & 24.29 \\
4 & 18 & 30 & 45 & 6.5 & 8 & 20 & 49.33 \\
46 & 19 & 30 & 15 & 8 & 10 & 20 & 43.87 \\
20 & 20 & 30 & 45 & 6.5 & 8 & 30 & 46.88 \\
63 & 21 & 1 & 45 & 8 & 10 & 30 & 44.28 \\
41 & 22 & 1 & 15 & 6.5 & 10 & 20 & 53.27 \\
14 & 23 & 30 & 15 & 8 & 10 & 30 & 48.81 \\
36 & 24 & 30 & 45 & 6.5 & 8 & 20 & 47.00 \\
23 & 25 & 1 & 45 & 6.5 & 8 & 30 & 31.96 \\
45 & 26 & 1 & 15 & 8 & 10 & 20 & 37.29 \\
30 & 27 & 30 & 45 & 8 & 10 & 30 & 46.37 \\
1 & 28 & 1 & 15 & 6.5 & 8 & 30 & 46.53 \\
21 & 29 & 30 & 15 & 8 & 8 & 80 & 30.52 \\
49 & 30 & 1 & 15 & 6.5 & 8 & 8 & 53.26 \\
19 & 31 & 1 & 45 & 6.5 & 8 & 10 & 46.61 \\
47 & 32 & 1 & 8 & & & 20 \\
\hline
\end{tabular}

the R-square $0.933,0.943$ and 0.919 for mean, standard deviation and coefficient of variance respectively. These values were found to be in reasonable agreement with standards. Retention time is the only factor that is not involve in interaction among the four significant factors selected out of the five factors under consideration.
The model equation is given by:

$Y=\alpha A+\beta B+y C+\mu D+8 E+\partial A B+\varnothing C E+\partial A D+\varepsilon B D+$ $\gamma D E+\hbar C D$

Substituting the coefficients from Table 4 to obtain the 
Table 3. Model effects contribution.

\begin{tabular}{lccc}
\hline Term intercept & Standard effect & Sum of square & \% contribution \\
\hline A & 5.62 & $0.505 \mathrm{E}+03$ & 2.52 \\
B & 9.91 & $1.57 \mathrm{E}+03$ & 7.83 \\
C & -19.4 & $6.03 \mathrm{E}+03$ & 30.1 \\
D & 22.6 & $8.20 \mathrm{E}+03$ & 40.9 \\
E & -0.764 & $1.47 \mathrm{E}+03$ & 7.33 \\
BD & 4.22 & $2.85 \mathrm{E}+02$ & 1.42 \\
CD & -4.54 & $3.30 \mathrm{E}+02$ & 1.64 \\
CE & 3.94 & $2.48 \mathrm{E}+02$ & 1.24 \\
DE & -4.13 & $2.73 \mathrm{E}+02$ & 1.36 \\
\hline
\end{tabular}

Table 4. ANOVA factorial model.

\begin{tabular}{lcccccl}
\hline Source & Sum of squares & DF & Mean square & F Value & Prob $>$ F & Remark \\
\hline Model & 18916.23 & 9 & 2101.80 & 98.48 & $<0.0001$ & Highly significant \\
A & 504.85 & 1 & 504.85 & 23.66 & $<0.0001$ & Highly significant \\
B & 1571.43 & 1 & 1571.43 & 73.63 & $<0.0001$ & Highly significant \\
C & 6032.82 & 1 & 6032.82 & 282.67 & $<0.0001$ & Highly significant \\
D & 8200.89 & 1 & 8200.89 & 384.26 & $<0.0001$ & Highly significant \\
E & 1470.63 & 1 & 1470.63 & 68.91 & $<0.0001$ & Highly significant \\
BD & 284.64 & 1 & 284.64 & 13.34 & 0.0006 & Significant \\
CD & 330.01 & 1 & 330.01 & 15.46 & 0.0002 & Significant \\
CE & 248.26 & 1 & 248.26 & 11.63 & 0.0012 & Significant \\
DE & 272.70 & 1 & 272.70 & 12.78 & 0.0008 & Significant \\
\hline
\end{tabular}

Table 5. Model R-squared values.

\begin{tabular}{lc}
\hline Mean & 49.58 \\
Std. & 4.62 \\
C.V & 9.32 \\
R-Squared & 0.9330 \\
R-Squared & 0.9426 \\
R-Squared & 0.9193 \\
\hline
\end{tabular}

$\mathrm{CV}=$ Coefficient of variance, Std. $=$ Standard deviation .

generalized model equation that described the biogas yield as a function of design variables.

$\mathrm{Y}=49.6+5.62 \mathrm{~A}+9.91 \mathrm{~B}-19.4 \mathrm{C}+22.6 \mathrm{D}-0.764 \mathrm{E}+$ $3.94 \mathrm{CE}+4.22 \mathrm{BD}-4.13 \mathrm{DE}-4.54 \mathrm{CD}$

\section{Conclusion}

In this study, Optimum Design Parameter Determination of Biogas Digester Using Human Faeces Feedstock has been presented. In the considered Digester, the optimum design parameters were obtained at run 4 with a maximum yield of $86.24 \%$. The most sensible variable parameter was found to be the mixing ratio with high coefficient of sensitivity. The R-square values for the mean, standard deviation and coefficient of variance were found to be in reasonable agreement with standards. Retention time is the only factor that is not involved in interaction among the five factors considered within the research scope.

\section{REFERENCES}

Deublein D, Steinhauser A (2008). Biogas from waste and renewable resources. Weinheim: WILEY-VCH Verlag GmbH Co.

John FL (2012). Methane digester for fuel gas and fertilizer. http://journeytoforever.org/biofuel_library/MethaneDigesters/MD3.htm I. access date $26 / 04 / 2013$.

Montgomery DC (2001). Introduction to Statistical Quality Control, Wiley, New York.

Montgomery DC (2005). Design and Analysis of Experiments, Wiley, Hoboken, N.J.

United Nations Children's Fund (2006). Progress for children: A yearly report.

World Health Organization (2010). Water, sanitation and health: health through safe drinking water and basic sanitation. http://www.who.int/water_sanitation_health/mdg1/en/index.html.

Wu CFJ, Hamada M (2000). Experiments: Planning, Analysis and Parameter Design Optimization, Wiley, New York. 